\title{
PRINCIPIOS DEL PROCEDIMIENTO DE APLICACIÓN DE MEDIDAS DE PROTECCIÓN DE DERECHOS DE NIÑOS Y NIÑAS*
}

\author{
PRINCIPLES OF THE PROCEDURE FOR APPLYING
}

MEASURES TO PROTECT RIGHTS OF CHILDREN

PRINCIPES DE LA PROCÉDURE D’APPLICATION

DES MESURES DE PROTECTION DES DROITS DES ENFANTS

Francisco Estrada VÁsquez ${ }^{* *}$

\begin{abstract}
RESUMEN
El trabajo propone un conjunto de principios especificos del procedimiento de aplicación de medidas de protección de derechos de niños y niñas, los que están llamados a erigirse en el eje teleológico de una hermenéutica que aplique la Convención sobre los Derechos del Niño y los demás tratados internacionales que configuran el marco normativo, de forma que nuestro sistema judicial proteja realmente los derechos de los niños. Para esto se examinan tanto aquellos principios denominados como tales por el legislador de familia como, a partir de la revisión de la normativa, algunos que sin ser explicitados como tales, nos parecen contribuyen a estructurar el edificio de la protección jurisdiccional de derechos de la niñez.
\end{abstract}

PalabRas CLAVE: Protección de derechos - Derechos de los niños - Medidas de protección

ABSTRACT

The paper proposes a set of specific principles of the procedure for applying measures to protect rights of children, which are meant to become the core of the teleological hermeneutics applying the Convention of the Rights of the Children and other international treaties shaping the regulatory framework, so that our judicial system really protects the rights of children. For this purpose, this paper examine both the principles explicitly recognized as such by the legislator, as well as principles arising from the review of the legislation, that without being explicitly recognized as such, help structuring the building of judicial protection of rights of children.

KEYWORDS: Child protection - Child's rights - Protection's procedure rules

RÉSUME:

Cette chronique propose un ensemble de principes spécifiques de la procédure d'application des mesures de protection des droits des enfants, ce qui ont le but de devenir le noyau téleologique d'une herméneutique pour mettre en place la Convention sur les droits des enfants et d'autres traités internationaux qui sont partie du cadre normatif, pour aboutir à une réelle protection des droits des enfants par notre système judiciaire.

MOTS CLÉS: Protection des $\mathrm{tf}$ droits - Droits des enfants - Mesures de protection

* Artículo recibido el 29 de octubre de 2015 y aceptado para su publicación el 27 de noviembre de 2015.

${ }^{* *}$ Licenciado en Derecho, Pontificia Universidad Católica de Chile. Magíster en Derecho de Familia, Infancia y Adolescencia, Universidad Diego Portales. Ex Director Nacional del Servicio Nacional de Menores. Profesor de Derecho Civil, Universidad Central. Correspondencia a: Correo electrónico franciscojestrada@gmail.com. Este trabajo es parte de un proyecto de investigación sobre la protección de derechos del niño. 


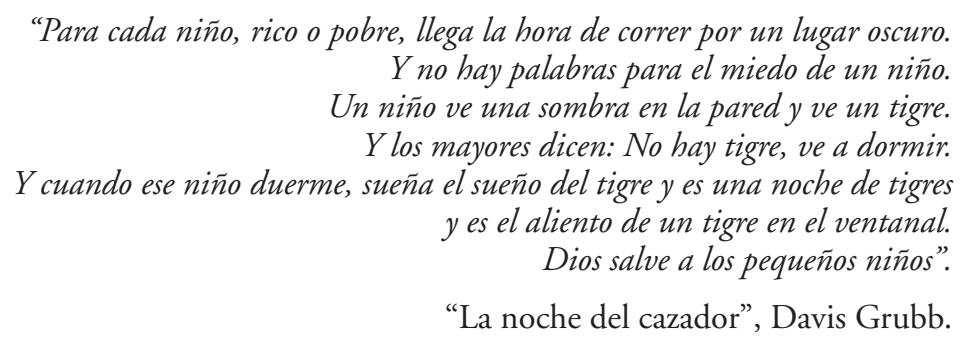

\section{INTRODUCCIÓN}

Un área del derecho que ha carecido de suficiente atención dogmática es la del derecho de infancia. La lenta desaparición del derecho de menores comenzó en 1990 con la entrada en vigencia de la Convención sobre Derechos del Niño -en adelante, la Convención-, pero su defunción no se vio seguida de la emergencia de un corpus sistemático que le reemplazase. Es así como a veinticinco años de esa fecha aún está en vigencia de la ley de menores ${ }^{1}$. En materia procesal, sin embargo, la ley No 19.968, de Tribunales de Familia, produjo una reforma de magnitud al instaurar mínimas reglas de debido proceso en el marco de juicios orales ante una nueva judicatura que se esperaba ofreciera una respuesta oportuna y especializada a la problemática de la infancia ${ }^{2}$. Pero esta reforma procesal en lo concerniente al procedimiento para aplicación de medidas de protección a niños y niñas gravemente vulnerados en sus derechos ha carecido de escrutinio académico. Con el propósito de aportar a esta necesaria revisión ofrecemos aquí una proposición de principios específicos de este procedimiento, que están llamados a erigirse en el eje teleológico de una hermenéutica que aplique la Convención y los demás tratados internacionales atingentes y que configuran el marco normativo, de forma que nuestro sistema judicial proteja realmente los derechos de los niños.

\section{Generalidades}

Este planteamiento de un examen dogmático de los principios imperantes en sede proteccional, se hace de forma consciente del momento en el que se encuentra el debate legal alrededor de la noción de principios, y su lugar en el universo de los sistemas jurídicos. Este momento se caracteriza por problematizar el uso de este instituto jurídico, en razón de la equivocidad del uso de la apelación argumentativa a "principios". Parte de estos problemas, se estima, se originan en un cierto apuro por argumentar desde principios saltándose la compleja gama de técnicas,

\footnotetext{
${ }^{1}$ La ley No 16.618, Ley de Menores, Diario Oficial, 8 de marzo de 1967, aunque sus rasgos de continuidad sustantiva -según veremos más adelante- la deberían datar en 1928 con la ley No 4.447 de la que no es más que una reorganización.

2 Vid. Mensaje del Ejecutivo en Biblioteca del Congreso Nacional (2004). Historia de la ley No 19.968, que crea los tribunales de familia.
} 
instituciones y reglas, según fundadamente anotan Coloma, Atria y Aldunate ${ }^{3}$. Los principios, producto de un cierto voluntarismo, parecen querer ser cartas de triunfo que sobrepasen reglas e institutos positivos, y este uso, me parece, es consistente con el mito del legislador racional que $\mathrm{Nino}^{4}$ entreviese tan lúcidamente hace ya unos cuarenta años.

Pero tomar nota del problema en el uso del argumento principios no es óbice para intentar colegir del conjunto de normas si es que de verdad es posible considerar que hay algunos que merecen la pena de ser apreciados como tales.

Dice García de Enterría ${ }^{5}$ que los principios jurídicos:

"no proceden por deducción de primeras verdades morales, sino que son principios técnicos, que articulan sobre todo el mecanismo básico del Derecho, que son las instituciones; y su desarrollo y perfección es un fruto de la vida jurídica, un hallazgo a través del manejo de problemas concretos, y es la obra por excelencia de la jurisprudencia y de la doctrina, actuando en recíproca interrelación".

Los principios, así, emergerían desde el multiforme universo de los casos a través del escrutinio analítico del académico, quien los configuraría como los pilares de su edificio dogmático. Producidos de esta manera, el rol de los principios sería, por un lado, de central herramienta hermenéutica, por el otro, de estructura sistematizadora que ofrece unicidad allí donde el ojo lego sólo ve diversidad; y los principios permitirían enlazar la realidad fáctica, la realidad normativa y la realidad valorativa en un eje que tensiona a los tres vértices.

Por otro lado, hablar de principios es relevante porque significa hablar de los valores a la base de determinada regulación, los objetivos de política pública dentro de los que determinada normativa constituye una herramienta. Los principios permiten escapar de la tentación fetichista ${ }^{6}$ de meramente refrasear la ley, al modo de los manuales al uso sobre tribunales de familia, para, en cambio, ofrecer un edificio dentro del que insertar las diferentes reglas.

Para estos efectos, nos parece útil la noción de Dworkin de los principios como "mandatos de optimización que se caracterizan porque pueden ser cumplidos en

\footnotetext{
${ }^{3}$ Coloma Correa, Rodrigo (2011). "Los principios como analgésicos ante lagunas, inconsistencias e inequidades de los sistemas jurídicos”. En: Principios jurídicos. Análisis y crítica, Santiago: Thompson Reuters y Abeledo Perrot; Atria Lemaitre, Fernando (2011): "Lo que importa sobre los principios". En: Principios jurídicos. Análisis y crítica, Santiago: Thompson Reuters y Abeledo Perrot, y Aldunate Lizana, Eduardo (2011). "Principios jurídicos y neoconstitucionalismo". En: Principios jurídicos. Análisis y crítica, Santiago: Thompson Reuters y Abeledo Perrot.

${ }^{4}$ Nino, Carlos (1974). Consideraciones sobre la dogmática jurídica. México: Universidad Nacional Autónoma de México, pp. 48 y ss.

${ }^{5}$ García de Enterría (2004) citado en Vergara Blanco, Alejandro (2012). "Los principios jurídicos y la tarea de construir el Derecho Administrativo en clave científica”. Revista de Derecho Administrativo, No 6, p. 64.

6 Peña Gonzalez, Carlos (2002). "Prólogo". En: Introducción al Nuevo Proceso Penal, Santiago: Ediciones Universidad Diego Portales.
} 
diversos grados" y porque la medida ordenada de su cumplimiento no sólo depende de las posibilidades fácticas, sino también de las posibilidades jurídicas ${ }^{7}$.

Los textos normativos sobre protección de derechos del niño contienen algunas disposiciones que denominan principios y éstos serán algunos de los que escrutaremos. Pero también, a partir de la revisión de esa normativa, ofreceremos algunos principios que sin ser explicitados como tales, nos parece que contribuyen a estructurar el edificio de la protección jurisdiccional de derechos de la niñez.

Partamos delineando el marco normativo dentro del que pesquisaremos los principios. Nuestro sistema proteccional está compuesto, principal pero no exclusivamente, por tres cuerpos normativos: En primer lugar en la jerarquía normativa, por la Convención sobre los Derechos del Niño; por la ley No $16.618^{8}$, Ley de Menores, y por la ley No $19.968^{\circ}$, Ley de Tribunales de Familia. A nivel infralegal, las regulaciones más significativas son las del Acta 135-2010, que estatuye el Centro de Medidas Cautelares de Santiago y las Orientaciones Técnicas de Sename sobre Programas de Diagnóstico Ambulatorio (conocidos por las siglas DAM) y todas las otras del sistema proteccional. Y esta lectura debe integrarse con la citada Convención Americana de Derechos Humanos y el amplio corpus juris de instrumentos internacionales y observaciones generales que componen lo que se ha dado en denominar soft law. Destacan en este aspecto las recientes Directrices de NU para el cuidado alternativo.

No se contempla entre nosotros una regulación específica de los principios del procedimiento proteccional como sí la contiene, en derecho comparado, el reciente Código del Niño de Bolivia:

"Artículo 193. (Principios procesales). Además de los principios establecidos en el Artículo 30 de la Ley del Órgano Judicial, rigen en los procesos especiales previstos en este Código, los siguientes:

a. Especialidad. La justicia en materia de Niña, Niño y Adolescente, se desarrolla con la intervención de personal interdisciplinario especializado;

b. Desformalización. Se debe flexibilizar el procedimiento, evitando toda ritualidad o formalidad en el acceso a la justicia;

c. Presunción de Verdad. Para asegurar el descubrimiento de la verdad, todas las autoridades del sistema judicial deberán considerar el testimonio de una niña, niño o adolescente como cierto, en tanto no se desvirtúe objetivamente el mismo;

d. Reserva. En todo proceso se guardará la reserva necesaria para garantizar la dignidad e integridad de la niña, niño o adolescente;

\footnotetext{
${ }^{7}$ AleXY, Robert (1988). "Sistema jurídico, principios jurídicos y razón práctica”. Doxa. Cuadernos de Filosofía del Derecho, No 5, p. 143; Dworkin, Ronald (1984). Los derechos en serio. Barcelona: Ariel pp. 76 y ss.

${ }^{8}$ Ley No 16.618, Ley de Menores, Diario Oficial, 8 de marzo de 1967.

${ }^{9}$ Ley No 19.968, Ley de Tribunales de Familia, Diario Oficial, 30 de agosto de 2004.
} 
e. Concentración. Determina el desarrollo de la actividad procesal en el menor número de actos para evitar su dispersión;

f. Proporcionalidad. La aplicación de cualquier medida judicial a una niña, niño o adolescente debe estar relacionada con su edad y etapa de desarrollo, valorando toda circunstancia que pueda vulnerar sus derechos;

g. Transparencia. Los actos procesales se caracterizan por otorgar a las partes información útil y fiable, facilitando la publicidad de los mismos con el objeto de que la jurisdicción cumpla con la finalidad de proteger derechos e intereses que merezcan tutela jurídica; $y$

h. Pronunciamiento. La autoridad jurisdiccional tiene la obligación de pronunciarse sobre las peticiones presentadas por las partes, en cada etapa de los procesos".

El artículo 167 del Código de la Niñez y Adolescencia de Paraguay establece de modo similar, aunque más abreviado: "El procedimiento tendrá carácter sumario y gratuito, respetando los principios de concentración, inmediación y bilateralidad”.

\section{PRINCIPIOS}

\subsection{Interés superior del niño}

El principio del interés superior del niño -en adelante ISN-, surgido desde el derecho internacional y recogido en numerosos lugares de nuestro ordenamiento, posee también una específica expresión procesal.

El Comité de Derechos del Niño ${ }^{10}$ ha recientemente subrayado que el ISN posee una triple dimensión: constituye un derecho sustantivo, un principio jurídico interpretativo fundamental y una norma de procedimiento. Este último sentido es el que más nos importa para este trabajo. Dice el Comité:

“c) Una norma de procedimiento: siempre que se tenga que tomar una decisión que afecte a un niño en concreto, a un grupo de niños concreto o a los niños en general, el proceso de adopción de decisiones deberá incluir una estimación de las posibles repercusiones (positivas o negativas) de la decisión en el niño o los niños interesados. La evaluación y determinación del interés superior del niño requieren garantías procesales. Además, la justificación de las decisiones debe dejar patente que se ha tenido en cuenta explícitamente ese derecho. En este sentido, los Estados partes deberán explicar cómo se ha respetado este derecho en la decisión, es decir, quése ha considerado que atendía al interés superior del niño, en qué criterios se ha basado la decisión y cómo se han ponderado los intereses del niño frente a otras consideraciones, ya se trate de cuestiones normativas generales o de casos concretos".

${ }_{10}$ Comité de Derechos del Niño (2013). Observación general No 14. Sobre el derecho del niño a que su interés superior sea una consideración primordial (artículo 30, párrafo 1). CRC/C/GC/14. 
Este entendimiento es consistente con la propuesta del profesor Zermatten -ex presidente del mismo Comité- que veía en el ISN dos funciones: de control y de solución ${ }^{11}$.

La Corte Interamericana ha reforzado esta lectura garantista al afirmar:

"Toda decisión estatal, social o familiar que involucre alguna limitación al ejercicio de cualquier derecho de un niño o niña, debe tomar en cuenta el interés superior del niño y ajustarse rigurosamente a las disposiciones que rigen esta materia" ${ }^{\prime 2}$.

¿Qué consecuencias procesales se derivan entonces del artículo 16 de la ley No 19.968 y del artículo $3^{\circ}$ de la Convención?

En primer lugar, genera para los tribunales un deber de prioridad en el agendamiento de audiencias para las medidas de protección, similar al que el sistema procesal penal le ha dado a las audiencias de la ley No $20.084^{13}$. Consistente con ello, esta prioridad de agendamiento, en coherencia con el principio de inmediación, también exige que las sucesivas audiencias en que se realizará un juicio que incluye a niños se programen con cercanía en el tiempo, so riesgo de devenir en infracción de la inmediación y en una restauración fáctica de la escrituración o de su sucedáneo digital, el registro de audio.

En segundo lugar, el ISN refuerza el deber del plazo razonable de los procesos, deber que en materia de infancia es particularmente necesario dado que los tiempos de los niños son distintos a los tiempos adultos. En Fornerón contra Argentina, uno de los temas que la Corte Interamericana le reprocha a Argentina es justamente la demora en resolver, retraso que siempre jugó en contra del padre ${ }^{14}$. Este fenómeno también lo comenta respecto de dos emblemáticos casos españoles Benavente ${ }^{15}$. Esto no es exclusiva responsabilidad, por cierto, de la judicatura. Las listas de es-

\footnotetext{
11 "Criterio de control: el interés superior del niño sirve aquí para velar a que el ejercicio de derechos y obligaciones respecto de los niños sea correctamente efectuado. Es todo el dominio de la protección de la infancia que está concernida por este aspecto de control.

Criterio de solución: en el sentido en el que la noción misma del interés del niño debe intervenir para ayudar a las personas que deben tomar decisiones hacia los niños a elegir la buena solución”. ZERMATTEN, Jean (2003). El interés superior del niño. Del análisis literal al alcance filosófico. Informe de trabajo 3-2003, Institut International des Droits de l'Enfant, p. 11.

${ }^{12}$ Cfr. Corte IDH. Caso Fornerón e hija Vs. Argentina. Fondo, Reparaciones y Costas. Sentencia de 27 de abril de 2012 Serie C No. 242, párr. 48; Caso Furlan y Familiares Vs. Argentina. Excepciones Preliminares, Fondo, Reparaciones y Costas. Sentencia de 31 de agosto de 2012. Serie C No. 246, párr. 126; Condición Jurídica y Derechos Humanos del Niño. Opinión Consultiva OC-17/02 de 28 de agosto de 2002. Serie A No 17, párr. 65.

${ }^{13}$ Ley No 20.084, establece un sistema de responsabilidad de los adolescentes por infracciones a la ley penal, Diario Oficial, 7 de diciembre de 2005.

${ }^{14}$ Fornerón e hija Vs. Argentina, No 66.

15 Benavente Moreda, Pilar (2011). "Riesgo, desamparo y acogimiento de menores: Actuación de la administración e intereses en juego". Anuario de la Facultad de Derecho de la Universidad Autónoma de Madrid, No 15, pp. 15-62.
} 
pera para pericias -responsabilidad del Servicio Médico Legal o de programas del circuito de Sename, según qué institución las efectúe- impactan negativamente en el cumplimento del plazo razonable.

En tercer lugar, el ISN contiene un deber argumentativo preciso que recae sobre el juez al sentenciar. Omitir esta argumentación constituye una infracción normativa que puede influir en lo dispositivo de la sentencia y que, en tal caso, amerita la casación del fallo. Así lo ha entendido la Corte Suprema al sostener:

"Décimo: Que, en estas materias debe tenerse siempre en consideración el Interés Superior del Niño, como principio fundamental e inspirador del ordenamiento jurídico nacional, de relevancia transversal en la legislación de familia y de menores. Así lo dispone, por lo demás, el artículo 16 de la ley $N^{o} 19.968$ y aún cuando constituya un concepto indeterminado, cuyo alcance se aprecia cuando es aplicado al caso concreto, puede afirmarse que consiste en el pleno respeto de los derechos esenciales del niño, niña o adolescente, para procurar el cabal ejercicio y protección de sus derechos esenciales. Dicho principio se identifica con la satisfacción plena de los derechos de los menores, en su calidad de personas y sujetos de derechos, identificándose de esta manera 'Interés Superior' con los derechos del niño y adolescente y si bien éste se encuentra presente y se proyecta en todo el sistema jurídico, al erigirse como una garantía de amplitud tal que obliga no sólo al legislador sino que a todas las autoridades e instituciones y a los propios padres, interesa de sobremanera el aporte que tiene en el ámbito de la interpretación, al constituir una norma de resolución de conflictos jurídicos, permitiendo decidir asi situaciones de colisión de derechos, según su contenido y la ponderación de los que se encuentran en pugna (...).

Undécimo: Que no obstante la trascendencia antes anotada del principio en estudio, cabe destacar que en la especie los jueces del grado no se han hecho cargo en sus motivaciones de la situación del menor - desde la perspectiva de su interés superior-limitándose en sus reflexiones a reconocer por sobre otra consideración el derecho legal de la madre a ejercer el cuidado del hijo, al extremo de limitarse en su análisis sólo al descarte de causales de inhabilidad por parte de la progenitora, para concluir que a ella debe confiarse su cuidado, sin atender a la condición del niño, como sujeto de derecho de especial protección por el legislador.

Duodécimo: Que tal proceder desconoce la importancia que dicho principio reviste en la resolución del caso en el que ha debido tenerse en especial consideración la situación del menor el que ha permanecido desde su nacimiento con su padre, con el cual ha generado los vínculos de apego que no ha desarrollado con la madre, bajo cuya custodia se vislumbra desprotección"16.

El máximo tribunal ha complementado lo anterior preceptuando:

"[e]s un principio fundamental en nuestro ordenamiento jurídico, tal como lo dispone el artículo 16 de la ley $N^{o} 19.968$ y, aun cuando su concepto sea indeterminado, puede afirmarse que el mismo alude a asegurar el ejercicio y protección de los derechos fundamentales de los menores y a posibilitar la mayor satisfacción de todos los aspectos de su vida, orientados

${ }^{16}$ Corte Suprema, “Meza con De la Rivera”, 16 de agosto de 2010, rol No 4307-2010. 
al desarrollo de su personalidad. Dicho principio se identifica con la satisfacción plena de sus derechos, en su calidad de personas y sujetos de éstos, identificándose de esta manera 'interés superior' con los derechos del niño y adolescente. Si bien se encuentra presente y se proyecta en todo el sistema jurídico, al erigirse como una garantía de amplitud tal que obliga no sólo al legislador sino que a todas las autoridades e instituciones y a los propios padres, interesa de sobremanera el aporte que tiene en el ámbito de la interpretación, al constituir una norma de resolución de conflictos jurídicos, permitiendo decidir asi situaciones de colisión de derechos, según su contenido y la ponderación de los que se encuentran en pugna. En este sentido, cobran especial interés los efectos que el referido principio produce en el marco de las relaciones parentales, en las que, por un lado, se encuentra el derecho y responsabilidad de los padres de cuidar y educar a los hijos y por otro, la necesidad de brindarles protección y garantizar su desarrollo" ${ }^{\prime \prime}$.

Pero otra forma de infringir este principio, distinta a la omisión, es su uso meramente retórico. Como ha señalado la Corte Interamericana:

"[n]o es suficiente con hacer referencia a que ha sido tomado en consideración el interés superior del niño en el momento de adoptar una decisión que le afecte (...). La determinación de cuál sea el interés superior del niño en cada caso concreto deberá realizarse de modo razonado y estar justificado sobre la base de la protección de los derechos del niño, así como quedar oportunamente sustentado en el procedimiento, con la documentación que fuera relevante y pertinente" ${ }^{\prime \prime}$.

Es el tipo de reproche que le formula la Corte Suprema -en una de las escasas sentencias del máximo tribunal sobre esta materia- al juez de grado a propósito de una internación insuficientemente fundada:

"Noveno: Que, no obstante, la trascendencia antes anotada del principio en estudio, cabe destacar que en la especie los jueces del grado no se han hecho cargo en sus motivaciones de la situación de la menor - desde la perspectiva de su interés superior-limitándose en sus razonamientos a establecer que ella fue vulnerada gravemente en sus derechos, sin referirse a sus condiciones particulares y de vida, ni ponderar los efectos que la medida dispuesta le puede ocasionar, a fin de justificar la necesariedad de su aplicación"'?

En conclusión, tomarse en serio el interés superior del niño como principio hermenéutico exige evitar un uso meramente discursivo que reemplaza las antiguas nociones de "riesgo social" o "peligro material o moral" por una mera frase desprovista de sentido. A esta práctica argumentativa (judicial y de la administración) la hemos denominado el fraude de etiquetas. Creemos significativo un

\footnotetext{
${ }_{17}$ Corte Suprema, "Herrera con González y otros", 14 de enero de 2013, rol No 7150-2012.

18 Corte IDH. Caso Atala Riffo y Niñas Vs. Chile. Fondo, Reparaciones y Costas. Sentencia del 24 de febrero de 2012. Serie C No. 239, párrs. 109 y 110.

${ }^{19}$ Corte Suprema, "Medida de protección reservada", 9 de septiembre de 2010, rol No 5323-2010. Redacción del ministro Patricio Valdés.
} 
análisis argumentativo que aprecie cuatro dimensiones del uso justificatorio en sede adjudicatoria: la ubicación del "argumento ISN" en el cuerpo de la decisión, la magnitud de su desarrollo en la sentencia, su enlace con los hechos del caso y el vínculo que se establece con otros principios o normas.

Para asegurar un complejo uso argumentativo, el Comité de Derechos del Niño ha recomendado ${ }^{20}$ la consagración legislativa de listas de criterios. En línea con esta sugerencia he propuesto una redacción para nuestra futura ley de protección:

"Artículo 20. "El proceso de búsqueda del interés superior del niño o niña deberá siempre considerar:

1. Los deseos y sentimientos del niño o niña;

2. Sus necesidades fisicas, emocionales, y educativas;

3. Su edad, sexo, etnia, antecedentes familiares y otras características pertinentes;

4. Cualquier daño que haya sufrido o corra el peligro de sufrir;

5. El grado de capacidad de sus padres o adultos responsables de su cuidado;

La decisión administrativa, judicial o legislativa que se adopte deberá dejar constancia de estos criterios".

\subsection{Desformalización}

Uno de los avances más notables de la justicia de familia es su principio de desformalización, que procura impedir las dilaciones basadas en excesivas formalidades y solemnidades, o trámites repetitivos que se contraponen a la necesaria celeridad del procedimiento de protección de derechos. En materia proteccional, la desformalización tiene como objetivo dotar de amplias herramientas para responder oportunamente a problemas de muy heterogénea índole y difícil previsión. Así lo dispone el artículo 70 en su inciso $2^{\circ}$ al establecer:

"El requerimiento presentado por alguna de las personas señaladas en el inciso anterior no necesitará cumplir formalidad alguna, bastando con la sola petición de protección para dar por iniciado el procedimiento".

Carretta $^{21}$ comienza su ilustrativo trabajo ejemplificando con infancia la relevancia de la desformalización: "Se comprende, por ejemplo, que si lo tutelado es el derecho de un infante que ha sido vulnerado, se requiera la mayor diligencia procesal para restablecer aquel derecho".

${ }^{20}$ Comité de Derechos del Niño (2013), párr. 50-51.

${ }^{21}$ Carretta Muñoz, Francesco (2014). "La desformalización del proceso judicial de familia e infancia”. Revista de derecho (Valparaíso), Vol. 42, pp. 481-495. 
Pero son necesarias algunas precisiones. La primera es que desformalización aparece como sinónimo de celeridad. Sin embargo, hay formalidades que no demoran excesivamente los procesos. El sistema procesal penal posee varios ejemplos. Desde el reducido tiempo para el control de la detención (menos de 24 horas) a la disminución de la duración de la prisión preventiva. Añádase la reducción de la duración general de los procesos. Es decir, es posible concebir formalización y celeridad, no es correcto concebirlas per se como antinomias. La desformalización, en el estado actual de nuestras reformas, no es la única forma de alcanzar rapidez. Un entendimiento moderno de la gestión judicial puede ser mucho más relevante en este sentido.

La segunda precisión es que el razonamiento de Carretta contiene un juicio que no aparece justificado pero que lo subyace: la celeridad es buena, es positiva para la infancia. Ese tácito juicio requiere matices. Y es que este tipo de apreciaciones, bienintencionadas, poseen una oscura trayectoria en la historia de la infancia. Enlazan directamente con Samuel Gajardo ${ }^{22}$-la versión chilena de los salvadores del niño estadounidenses (Platt ${ }^{23}$ - y su apología de la distancia del derecho que debía caracterizar al juez de menores. ¿De qué hablamos cuando hablamos de celeridad como virtud? En los casos más complejos (en que hay ya daño o riesgo para la vida), la celeridad puede ser necesaria para una decisión (separar, o no, al niño de uno de sus padres, o de ambos). Pero el resto de las decisiones (sobre diagnóstico, plan de intervención, control de la medida) lo que exigen es tiempo para su adecuada construcción e internalización por parte de los actores del sistema familiar o institucional. Es preciso sopesar los informes, contrastarlos con información anterior, chequear las redes familiares, comunitarias y sociales del caso, diseñar planes alternativos, etc. Un ejemplo espero ilustre el error de concebir siempre la celeridad como virtud: hoy es habitual que los informes psicosociales relativos a un niño en procedimiento proteccional lleguen con escasa antelación y, a veces, el mismo día de la audiencia. ¿Cómo es posible preparar la discusión de dicha información? ¿Qué hace el tribunal si el informe no responde la pregunta que se le formuló o no contiene suficientes antecedentes justificatorios de la sugerencia? ¿Cuándo -en nuestra justicia de familia- se ha realizado un metaperitaje a alguno de estos informes? Se necesitarían abogados con una alta especialización en pericias -que hoy en día no existen- para poder leer estos informes e, inmediatamente, discutir de ellos en audiencia. La rapidez, en estos casos, opera como un mecanismo que,

\footnotetext{
22 "El juez no es un jurisconsulto sino un buen padre de familia" (Gajardo 1929: 95), debe obrar libre de "cubileteos legales" GAJARDO, Samuel (1929). Los derechos del niño y la tiranía del medio ambiente (Divulgación de la ley $N^{o}$ 4.447). Santiago: Imprenta Nascimento, p. 37. "Nada de escritos, rebeldías, ni traslados. Procedimiento verbal dice la Ley, sin forma de juicio". GAJARdo (1929), p. 37.

${ }^{23}$ Platt, Anthony (2001). Los Salvadores de los Niños o la Invención de la delincuencia. México: Ediciones Siglo XXI, tercera edición.
} 
en verdad, impide estructuralmente se realice un debate informado del que emerja una verdad de calidad que le permita al sentenciador tomar la mejor decisión.

Algunas decisiones exigen celeridad, otras, en cambio, necesitan tiempo.

A consecuencia de esas dos precisiones se sigue que no necesariamente la desformalización es positiva en términos de protección a la infancia. Aunque esto parece ser contraintuitivo, baste tener presente que hoy, en diversos ámbitos -entrevista a niños, p. ej.- el horizonte de mejoras pasa justamente por contar con formas, con protocolos, con regulaciones y su ausencia es considerada un déficit.

Así, coincido con Carretta ${ }^{24}$ en cuanto a que la desformalización no justifica la contravención explícita de la ley procedimental, ni la arbitrariedad en la negación de demandas, o bien la adulteración de la naturaleza jurídica de las resoluciones judiciales, pues todo ello atenta contra el derecho a un debido proceso, expresado en un procedimiento legalmente tramitado. El principio de legalidad no desaparece con el principio de desformalización. Las formas son también necesarias para salvaguardar los derechos de niños vulnerados.

\subsection{Juez con facultades amplias}

Ya la primera normativa nacional especial de protección de menores, la ley No $2.675^{25}$, sobre protección a la infancia desvalida, contenía atribuciones para la actuación tutelar, de oficio del tribunal, en su artículo $6^{\circ}$ :

"Podrá el juez proceder en la forma establecida en el artículo $4^{\circ}$ a petición de cualquier consanguineo del menor, de1 defensor de menores, del ministerio público i aun de oficio"n.

El mismo contenido se traspasa a la ley No 4.447, que en su artículo 24 establece:

"Art. 24. El juez podrá ejercer las facultades que le otorga esta ley, a petición del Director General de Protección de Menores, de cualquiera otra persona y aún de oficio".

Y de ahí pasa al artículo 31 de la ley No $16.618^{27}$ :

"Artículo 31.- El juez podrá ejercer las facultades que le otorga esta ley, a petición de la Policía de Menores, de los organismos o entidades que presten atención a menores, de cualquiera persona y aun de oficio. En el ejercicio de estas facultades podrá el juez ordenar las diligencias e investigaciones que estime conducentes".

${ }^{24}$ Carretta Muñoz (2014).

${ }^{25}$ Ley No 2.675, sobre protección a la infancia desvalida, Diario Oficial, 4 de septiembre de 1912.

${ }^{26}$ A su turno, los artículos $1^{\circ}$ a $3^{\circ}$ construían presunciones de derecho de abandono y depravación ante las que se permitía actuar en la forma que indicaba el artículo $4^{\circ}$ : "En los casos de los artículos precedentes, el menor será confiado provisionalmente o al cuidado de un establecimiento de reforma, al representante legal de una institución de beneficencia con personalidad jurídica, o de cualquier otro establecimiento autorizado a este efecto por el Presidente de la República, hasta que el juez resuelva en definitiva". La institución más grande en dicha época era la Sociedad Protectora de la Infancia, aún en funcionamiento.

${ }^{27}$ Ley No 16.618, Ley de Menores, Diario Oficial, 8 de marzo de 1967. 
He ahí, entonces, que desde hace más de cien años nuestra judicatura ha contado, en materia de protección de menores/niños con amplias facultades de intervención.

Estas amplias facultades también existen en la experiencia comparada ${ }^{28}$.

Hoy, este principio se expresa en el artículo 13, de la Ley de Tribunales de Familia, dentro del Párrafo 10 "De los principios del procedimiento", que establece:

"Artículo 13.- Actuación de oficio. Promovido el proceso y en cualquier estado del mismo, el juez deberá adoptar de oficio todas las medidas necesarias para llevarlo a término con la mayor celeridad. Este principio deberá observarse especialmente respecto de medidas destinadas a otorgar protección a los niños, niñas y adolescentes y a las victimas de violencia intrafamiliar".

Pero este principio cuenta con variadas expresiones. En primer lugar, el artículo 17 , en su parte final, permite al tribunal acumular incluso asuntos no sometidos al mismo procedimiento con explícita mención al procedimiento proteccional. También es expresión de este principio la facultad consagrada en el artículo 70 de iniciar de oficio el procedimiento proteccional. En tercer lugar, este principio se encuentra configurado también en el establecimiento preciso de medidas cautelares del artículo 71, que también pueden ser adoptadas de oficio.

Es en base a los artículos 13 y 71 que la Corte de Apelaciones de Concepción acoge una apelación y le reprocha a la jueza de familia su inactividad en orden a proteger:

"7.- Que en la especie, no se advierte que el Juzgado de Familia en cumplimiento de la actuación de oficio consagrada en el artículo 13 de la ley $N^{o} 19.968$ haya adoptado las medidas adecuadas para resolver la cuestión planteada por el órgano encargado de llevar a cabo la terapia reparatoria dispuesta por el mismo tribunal en el mes de febrero de 2010, como no sea el certificado que suscribe la Consejera Técnica suplente doña Jasna Silva Soto de 13 de agosto de 2010, en la que deja constancia que el Ministerio Público lleva a cabo una investigación por abuso sexual en contra de Mauricio $A$. R. R., información que fue proporcionada por una secretaria de dicho organismo que no se identifica.

Con esa escasa información la juez a quo no dio lugar a adoptar la medida de protección pedida por el PROEMI y remite a dicho organismo y a la madre del niño a efectuar la petición al Ministerio Público.

8.- Que, sin perjuicio de las medidas que el Ministerio Público puede requerir al juez de garantía para la protección de la víctima en el marco de su investigación, es lo cierto que el juez de familia no puede soslayar la responsabilidad que la ley le ha otorgado enviando al solicitante a plantear su petición ante otra institución, que es lo que ocurrió en la sentencia

\footnotetext{
${ }^{28}$ Por ejemplo el Código del Niño de Bolivia, artículos 216, 225; el Código de la Niñez y Adolescencia de Costa Rica, artículo 149; Código de la Niñez y Adolescencia de Ecuador, artículo 278; el Código de la Infancia y la Adolescencia de Colombia, artículo 121; el Código de la Niñez y Adolescencia de Paraguay, artículo 167.
} 
recurrida, debiendo, en consecuencia, hacerse cargo de la petición que se le efectúa, acogiéndola o rechazándola, indicándose en cada caso los fundamentos tenidos a la vista para cada caso ${ }^{229}$.

Una cuarta forma en que se concreta este principio en nuestro ordenamiento reside en que no se encuentra sujeto a los límites de la ultra petita. Así lo ha indicado acertadamente la Corte de Santiago:

"Noveno: Que asi las cosas, de relacionar la norma del inciso segundo del artículo 234 del Código Civil con la regla del $N^{o} 7$ del artículo $8^{\circ}$ y 30 de la ley $N^{o} 19.968$, se infiere que el juez de la causa no se encuentra, en estas materias, constreñido por las peticiones concretas que se contienen en la solicitud de protección que dio inicio a la causa, desde que el fin que se persigue es la protección del menor y el pleno respeto de sus derechos. Con todo, el juez puede, con estricto apego a la legislación vigente, disponer incluso de oficio las medidas necesarias para el resguardo y amparo de los niños, las que en el caso de autos, aparecen plenamente justificadas"

Finalmente, también el artículo 80 permite la actuación de oficio del tribunal para suspender, modificar o hacer cesar medidas, subrayando así el carácter de cosa juzgada formal que poseen las sentencias en materia proteccional.

"Articulo 80.- Suspensión, modificación y cesación de medidas. En cualquier momento en que las circunstancias lo justifiquen, el juez podrá suspender, modificar o dejar sin efecto la medida adoptada, de oficio, a solicitud del niño, niña o adolescente, de uno o de ambos padres, de las personas que lo tengan bajo su cuidado o del director del establecimiento o responsable del programa en que se cumple la medida".

Es ésta una facultad clásica de los órganos de protección. Baste traer a la vista el artículo 38 de la Ley argentina de protección:

"Artículo 38.- Extinción. Las medidas de protección pueden ser sustituidas, modificadas o revocadas en cualquier momento por acto de la autoridad competente que las haya dispuesto y cuando las circunstancias que las causaron varien o cesen".

El único presupuesto necesario para que proceda el ejercicio de esta intensa facultad está expresado en términos amplios: "en que las circunstancias lo justifiquen". Con esto debiera entenderse que existan antecedentes psicosociales que informen al tribunal de avances del proceso de intervención. No creo posible interpretar esta norma como un espacio de absoluta arbitrariedad judicial. La sana crítica, el estándar probatorio exigible en el sistema de familia en conformidad al artículo 32, impone una doble limitación a la argumentación del juez.

${ }^{29}$ Corte de Apelaciones de Concepción, "Medida de protección reservada", 18 de enero de 2011, rol No 495-2010. Redacción del Ministro Suplente Valentina Salvo Oviedo.

30 Corte de Apelaciones de Santiago, "Medida de protección reservada", 2 de noviembre de 2010, rol No 1878-2010. Redacción de la Ministra señora Jessica González T. 
En primer lugar, sus decisiones -sobre suspender, modificar o cesar medidas de protección- "no podrán contradecir los principios de la lógica, las máximas de la experiencia y los conocimientos científicamente afianzados". Lo que, para la cuestión examinada, exige al tribunal un soporte específico de su decisión, un fundamento psicosocial del momento en que ésta será, generalmente, el tipo de intervención desarrollada. Pero lo mismo puede predicarse si la medida impone tratamiento médico o psiquiátrico. Y esa información, que soporte la decisión, debe introducirse al procedimiento, idealmente, oralmente en audiencia, y muy excepcional y supletoriamente, por escrito.

Una segunda limitación que dimana del artículo 32 es que "La sentencia deberá hacerse cargo en su fundamentación de toda la prueba rendida, incluso de aquella que hubiere desestimado, indicando en tal caso las razones tenidas en cuenta para hacerlo". Es decir, el fundamento de la decisión debe hacerse cargo de todas las probanzas incorporadas en sede cumplimiento. De ahí que resulte consistente la exigencia del inciso 20 del artículo 76: "En la ponderación de dichos informes, el juez se asesorará por uno o más miembros del consejo técnico".

Esto es, que no sólo debe recibir información sino, además y cosa distinta a proveer con un "a sus autos", debe, se le exige, que la aprecie con la colaboración del consejo técnico. Del conjunto de esas apreciaciones debe hacerse cargo, por explícito mandato del artículo 32 al ejercer la facultad del artículo 80 .

Cuenta así, la judicatura proteccional con un claro mandato legal para ejercer atribuciones que hagan cesar, evitar o disminuir la grave vulneración de derechos que el niño vive o puede vivir. Es decir, que estas herramientas normativas cuentan con un telos, que las orienta y limita, y al que se ha de recurrir para fines hermenéuticos.

\subsection{Oir a los niños}

El artículo 12 de la Convención fue repetido en el artículo 16 de la ley No 19.968, pero con un detalle, se ubicó junto al interés superior en el mismo artículo. Esta específica inserción debiera reforzar la lectura propuesta por Couso ${ }^{31}$ en orden a que todo proceso de búsqueda del ISN pasa por el derecho del niño a ser escuchado. El derecho a ser oído es primordial, sobre todo tratándose de procesos en los que se indaga sobre un asunto donde la principal víctima ha sido un niño, niña o adolescente. El derecho a ser oído, establecido en el artículo 12 de la Convención sobre Derechos del Niño, debe ser leído en consonancia con los artículos $3^{\circ}, 4^{\circ}, 5^{\circ}, 13,14,15$ y 19 de la misma convención. Se trata de la manifestación más potente del reconocimiento de la calidad de sujeto de derechos y de ciudadanía, de los niños, niñas y adolescentes.

${ }^{31}$ Couso Salas, Jaime (2006). "El niño como sujeto de derechos y la nueva Justicia de Familia. Interés superior del niño, autonomía progresiva y derecho a ser oído". Revista de Derechos del Niño, Vol. 3-4, pp. 145-166. 
Oír a los niños no significa sólo escuchar lo que verbalmente nos pueden comunicar $^{32}$. Es necesario entender este derecho como un proceso complejo, que involucra lenguaje verbal y no verbal, reacciones y tiempos distintos, y un desarrollo cognitivo y emocional no adultista, sino propio de la infancia y adolescencia. No se puede medir con parámetros de racionalidad adulta la capacidad de los niños para expresar su opinión. Este punto es central, pues de otra forma se puede llegar a concluir de forma errónea que sólo quienes puedan expresarse verbalmente y de forma racional (adulta) pueden ser oídos. Nada más lejos de lo realmente establecido en la Convención. Hacer pie en este entendimiento -que el Comité remarcó al insistir en la comunicación no verbal ${ }^{33}$ - podría desafiar la práctica hoy consolidada del registro de audio como el sistema de registro en justicia de familia, ya que en materia de niños, la buena práctica-como lo reconocen las modalidades de sala Gesell hoy en estudio- es el registro audiovisual.

Entre nosotros quizá el caso que mejor muestra la relevancia de este principio en la solución de casos complejos se encuentra en el fallo de la Corte de Valdivia de 14 de mayo de $2009^{34}$, que sostiene:

"DÉCIMOCUARTO: Que, en primer término, no se tuvo en cuenta la opinión del menor. Es completamente cierto que la autonomía individual no se reconoce plenamente por el ordenamiento jurídico nacional sino hasta los dieciocho años, y que por lo mismo esa opinión nunca podrá considerarse definitivamente determinante. Pero la ley reconoce que el proceso de formación de la conciencia humana es gradual, y por lo mismo exige que la opinión del menor sea objeto de consideración judicial, a la luz de su edad y de sus capacidades intelectuales concretas.

Teniendo el niño G. N. once años de edad, y habiendo vivido antes la experiencia de un tratamiento de quimioterapia, estima esta Corte que, aunque fuera nada más que para una mejor ilustración, debió consultarse su parecer. Asi lo dispone, desde luego, el artículo 12 de la Convención sobre los Derechos del Niño (ley chilena en virtud del decreto 830 RR.EE. de fecha 27 de septiembre de 1990) que establece que '1. Los Estados Partes garantizarán al niño que esté en condiciones de formarse un juicio propio el derecho de expresar su opinión libremente en todos los asuntos que afectan al niño, teniéndose debidamente en cuenta las opiniones del niño, en función de la edad y madurez del niño. 2. Con tal fin, se dará en particular al niño oportunidad de ser escuchado, en todo procedimiento

\footnotetext{
${ }^{32}$ Cfr. Lansdown, Gerison (2005). La evolución de las facultades del niño. Unicef y Save the Children: Instituto de Investigaciones Innocenti de UNICEF.

33 Comité de Derechos del Niño (2009). Observación general No 12. El derecho del niño a ser escuchado. CRC/C/GC/12, No 21.

34 Corte de Apelaciones de Valdivia, "Medida de protección reservada", 14 de mayo del 2009, rol No 103-2009. Redacción del abogado integrante Juan Andrés Varas. Un amplio comentario en VIVANCO MARTíneZ, Angela (2009). "Negativa de un menor de edad y de su familia a que este reciba una terapia desproporcionada o con pocas garantías de efectividad. Apelación de medida de protección otorgada por la jueza de familia de Valdivia. Sentencia de la I. Corte de Apelaciones de Valdivia, de 14 de mayo de 2009". Revista Chilena de Derecho, Vol. 36, No 2, pp. 399-440.
} 
judicial o administrativo que afecte al niño, ya sea directamente o por medio de un representante o de un órgano apropiado, en consonancia con las normas de procedimiento de la ley nacional'. Asi lo establece, asimismo, el artículo 16 ley $N^{\circ} 19.968$, que crea los Tribunales de Familia: 'Interés superior del niño, niña o adolescente y derecho a ser oído. Esta ley tiene por objetivo garantizar a todos los niños, niñas y adolescentes que se encuentren en el territorio nacional, el ejercicio y goce pleno y efectivo de sus derechos y garantías. El interés superior del niño, niña o adolescente, y su derecho a ser oido, son principios rectores que el juez de familia debe tener siempre como consideración principal en la resolución del asunto sometido a su conocimiento. Para los efectos de esta ley, se considera niño o niña a todo ser humano que no ha cumplido los catorce años y, adolescente, desde los catorce años hasta que cumpla los dieciocho años de edad'. (El destacado es nuestro).

Asimismo, el Comité de Derechos del Niño ${ }^{35}$ insiste en una visión procesual del ejercicio de este derecho en vez de una perspectiva que podríamos denominar "insular" o de momento aislado, señalando: "133. Para que la participación sea efectiva y genuina es necesario que se entienda como un proceso, y no como un acontecimiento singular y aislado".

Finalmente, escuchar al niño, ha indicado el Comité exige también que: "el encargado de adoptar decisiones debe informar al niño del resultado del proceso y explicar cómo se tuvieron en consideración sus opiniones. La comunicación de los resultados al niño es una garantía de que las opiniones del niño no se escuchan solamente como mera formalidad, sino que se toman en serio"36.

Así lo estatuye el inciso 20 del artículo 75: "El juez deberá explicar claramente a las partes la naturaleza y objetivos de la medida adoptada, sus fundamentos y su duración".

En el sistema tutelar, el artículo 30 de la ley No 16.618 eximía al juez de este ingrato deber:

"Articulo 30.- Cuando se recoja un menor por hechos que no sean constitutivos de crimen, simple delito o falta, el Juez de Letras de Menores podrá, sin necesidad de llamarlo a su presencia, aplicarle alguna de las medidas indicadas en el articulo anterior, según más convenga a la irregularidad que presente".

No puede admitirse que el deber de escuchar al niño se cumpla con una incorporación meramente formularia en la sentencia, como esta sentencia de Juzgado de Familia de Copiapó, que decidió:

"Trigésimo primero: Que, además, para arribar a esta decisión se ha considerado también, especialmente, la opinión que el niño ha manifestado en la audiencia confidencial, principio también rector y transversal en la legislación y justicia de familia"37.

35 Comité de Derechos del Niño (2009).

36 Comité de Derechos del Niño (2009), párr. 45.

37 Juzgado de Familia de Copiapó, 4 de enero de 2013, RIT C-610-2012 y acumulada P-625-2012. 
Y este principio debe ser celosamente resguardado por las Cortes. Si ha sido parte del recurso la infracción a este deber, debe resolverse ese punto, no omitirse como ocurre con la decisión que recayó sobre la casación que impugnaba el fallo citado ${ }^{38}$.

En estos días el Poder Judicial construye salas Gesell en los nuevos edificios a lo largo del país y la Corte Suprema dicta un Acta regulatoria ${ }^{39}$. Sin embargo, más allá de una primera apreciación positiva, es necesario cuidar que esta práctica no rigidice e inmovilice el desarrollo tribunalicio de este derecho. En el sistema penal es ordinario que se realicen audiencias de control de detención en la posta central o en un centro asistencial si el imputado se encuentra allí internado. En la justicia de familia, y en particular en sede proteccional, hay casos en que la protección del niño exige justamente que la audiencia se desarrolle en un entorno cercano a él, como su casa, el hospital o el lugar donde se encuentre. La sala Gesell no es el cenit del respeto al derecho a ser oído, aunque por cierto constituye una valiosa práctica.

Finalmente, este principio -que es también un derecho- posee expresiones en términos de agendamiento de audiencias y cuestiones de infraestructura y otras decisiones de política pública que construyan un entorno que posibilite -y no impida- el ejercicio de la participación infantil. Me refiero, p. ej., a que se considere que el tiempo de la niñez, en todo nuestro país, por regla casi universal, significa que la mañana es tiempo escolar por lo que una audiencia que lo escuche, debiera ser una audiencia desarrollada en la tarde, de modo que no interfiera con la jornada escolar. Esto adquiere mayor relevancia en aquellos casos en que la intromisión estatal y judicial es abundante en pericias, intervenciones, entrevistas, etc. Pero también este principio exige a la magistratura llamada a proteger los derechos de niños vulnerados que no los deje, durante la espera de la audiencia o entrevista, en salas inidóneas, o permita que ingresen, para deleite de la prensa, a la vista de todos, luego de haber sido detenidos por la policía.

"El ambiente físico del tribunal -el tipo de muebles, la disposición y la ubicación de los asientos- puede directamente promover o impedir la comunicación. Puede ayudar a las partes en el proceso a comportarse como participantes activos o mantenerlas al margen en un rol más pasivo" ${ }^{40}$. Estas son palabras del Lord Chief of Justice del Reino Unido en torno al proyecto de los Youth Courts y que resultan plenamente aplicables en nuestra realidad.

\footnotetext{
${ }^{38}$ Corte Suprema, "Segovia con Valdivia”, 12 de junio de 2013, rol No 2522-2013. Redacción de abogado integrante Ricardo Peralta.

39 Acta No 237-2014.

${ }^{40}$ Home Office (2001). The Youth Court 2001. The Changing Culture of the Youth Court. Good Practice Guide. Disponible en: <https://www.justice.gov.uk/downloads/youth-justice/courts-and-orders/YouthCourt2001. pdf>. [Consulta: 15 octubre 2015].
} 
Estas no son preocupaciones sofisticadas del primer mundo. Considérese el Protocolo dictado por la Suprema Corte de México ${ }^{41}$ que dispone en su numeral 15 "Los juzgados":

"Las personas encargadas de impartir justicia se asegurarán de que en la sala de audiencias se disponga lo necesario para las niñas, los niños y los adolescentes tales como agua, asientos elevados, asistencia para niños y niñas con discapacidad, entre otros aspectos.

En la medida de lo posible, la disposición de la sala debe permitir que el niño, niña o adolescente pueda sentarse cerca de su madre, padre, tutor, tutora, persona de apoyo, abogado y abogada durante todo el procedimiento".

Son varios los edificios de juzgados de familia que cuentan con guardias de seguridad responsables del ingreso de las personas que asisten y que, careciendo de la más básica formación, no son agentes facilitadores del acercamiento de niños a los tribunales.

Como se ve, hay varias cuestiones vinculadas a los aspectos procedimentales operativos que exigen tomarse en serio este principio más allá de su aplicación estricta al interior del procedimiento ${ }^{42}$.

\subsection{Interdisciplina}

El Mensaje de la ley No 19.968 mencionaba dentro de los objetivos específicos para la nueva judicatura: "Que esa jurisdicción tenga un carácter interdisciplinario. Los tribunales que se crean, requieren tratar el conflicto en su integralidad, considerando los múltiples aspectos involucrados, a fin de ofrecerles soluciones también integrales".

Una serie de normas estatuyen la forma en que la judicatura de familia integra el conocimiento interdisciplinario habida cuenta que en los casos de vulneración de derechos las cuestiones a resolver poseen una dimensión jurídica pero, más importante aun, psicosocial que debe formar parte tanto de la sentencia como de la prueba rendida. Es así como el artículo $6^{\circ}$ indica que: "En cada juzgado de familia habrá un consejo técnico interdisciplinario integrado por profesionales especializados en asuntos de familia e infancia". Y añade luego como requisito para ser consejero técnico: “(...) se deberá acreditar experiencia profesional idónea y formación especializada en materias de familia o de infancia de a lo menos dos semestres de duración, impartida por alguna universidad o instituto de reconocido prestigio que desarrollen docencia, capacitación o investigación en dichas materias".

Lamentablemente el legislador fue ambiguo en lo concerniente a la disciplina o al tipo de estudios exigidos o al título profesional necesario para ejercer este cargo,

\footnotetext{
${ }^{41}$ Suprema Corte de Justicia de la Nación (2012). Protocolo de actuación para quienes imparten justicia en casos que afecten a niños. México.

${ }^{42}$ Más observaciones en esta línea en Estrada VÁsquez (2014).
} 
y recurrió a una ambigua fórmula. El poder judicial ha entendido en los procesos de contratación -correctamente en mi opinión- que las profesiones idóneas para este cargo son psicólogos y trabajadores sociales, aun cuando el Acta 93-2005 repite la ambigüedad sobre la multidisciplina. Luego, en lo concerniente a la producción de prueba, se establece en el artículo 45 inciso $4^{\circ}$ :

"Asimismo, el juez, de oficio o a petición de parte, podrá solicitar la elaboración de un informe de peritos a algún órgano público u organismo acreditado ante el Servicio Nacional de Menores que reciba aportes del Estado y que desarrolle la línea de acción a que se refiere el artículo $4^{\circ}, N^{\circ} 3.4$, de la ley $N^{\circ} 20.032$ cuando lo estime indispensable para la adecuada resolución del conflicto".

Es decir, el tribunal, cuando recurre a producir prueba propia está limitado a la que emana de un órgano público (el Servicio Médico Legal, p. ej.) o un programa de la red de instituciones colaboradoras acreditadas ante Sename en virtud de la ley No $20.032^{43}$. No puede, y el texto es claro en esto, recurrir a pericias privadas. La norma no contiene una excepción.

Para la valoración de la prueba rendida el artículo 64 en su inciso $6^{\circ}$ preceptúa: "Practicada la prueba, el juez podrá solicitar a un miembro del consejo técnico que emita su opinión respecto de la prueba rendida, en el ámbito de su especialidad”. Y aquí se producen al menos dos problemas. El primero, dada la revisada ambigüedad del artículo $6^{\circ}$ sobre la disciplina -que se replica en el Acta 93-2005-, no permite conocer con claridad quién es "especialista" en qué. Más bien, los jueces de familia recurren a quienes son de su confianza, o a sistemas internos de distribución de tareas, opacos -no públicos-y que impiden apreciar si en ese caso específico quién está sentado junto al juez es realmente un especialista en una particular problemática. El segundo problema es que las partes, en la actualidad, no tienen cómo conocer el currículum del consejero técnico ni cuentan con herramientas para objetarles en razón de carecer de especialidad. En los hechos resultan revestidos del carácter de "especialistas" sin que necesariamente lo sean.

La ley No 19.968 prosigue regulando la valoración de la prueba en el artículo 73:

"Audiencia de juicio. De conformidad a lo dispuesto en el artículo precedente, esta audiencia tendrá por objetivo recibir la prueba y decidir el asunto sometido a conocimiento del juez. En ella podrán objetarse los informes periciales que se hayan evacuado, pudiendo el juez hacerse asesorar por el consejo técnico".

Esa asesoría, a veces, se expresa en informes escritos, lo que resulta valioso para el debate informado por parte de las partes y entrega más información al tribunal de alzada o de casación, eventualmente.

${ }^{43}$ Ley No 20.032, establece sistemas de atención a la niñez y adolescencia a través de la red de colaboradores del Sename, y su régimen de subvención, Diario Oficial, 25 de julio de 2005. 
Finalmente, como ya vimos, el artículo 76 inciso $2^{\circ}$, respecto de los informes de cumplimiento de las medidas de protección establece que: "En la ponderación de dichos informes, el juez se asesorará por uno o más miembros del consejo técnico".

Normativamente, entonces, la ley No 19.968 procura instituir un sistema de integración interdisciplinaria en el conocimiento y resolución de las cuestiones del procedimiento proteccional, pero no lo realiza con claridad y precisión, aspectos que de lege ferenda podrían fortalecerse a partir de la evidencia nacional e internacional.

\subsection{Orientación a las consecuencias}

Este principio del derecho penal ${ }^{44}$, mutatis mutandi, existe también en la justicia de familia, y permite remarcar una directriz que cruza todo el nuevo derecho de infancia y que va en línea con una corriente al alza en el derecho comparado, pero que no suele erigirse en un principio porque no aparece expresado en cuanto tal en textos legales.

A la Ley de Tribunales de Familia no le da igual qué ocurre una vez se dicta sentencia en un procedimiento proteccional de niños o en uno de violencia intrafamiliar. No se trata, en estas materias, de un mero cumplimiento de reglas formales. Justamente este es el sentido del principio de desformalización.

Estas temáticas han coincidido en ser objeto de atención, en innovadores experiencias comparadas, de aproximaciones que buscan superar las respuestas tradicionales meramente formales. Me refiero a dos enfoques cercanos pero distintos: los tribunales orientados a las soluciones ${ }^{45}$ y la justicia terapéutica ${ }^{46}$.

Lo que el legislador muy claramente ha explicitado es su preocupación porque la judicatura ejerza un rol contralor intenso respecto del cumplimiento de las decisiones que se adopten en cuanto medidas de protección, de ahí que se le entreguen potestades amplias en fase cumplimiento. Esa preocupación del legislador no es sino la forma de honrar los compromisos estatales de protección asumidos en la Convención que exige del Estado tomar medidas para hacer efectivo el deber de protección (art. 4).

Un tribunal que adopta decisiones que sabe no protegerán ha renunciado a este principio. De ahí que el principio de orientación a las consecuencias en esta materia exige evitar incurrir en la ilusión de la protección y, por el contrario, por mandato legal y no por sensibilidad o decisiones subjetivas del juzgador, impone al jurisdicente atender a los escenarios que más probablemente ocurrirán a raíz de su resolución, una apertura a la realidad del sistema en el cual se insertan sus decisiones.

\footnotetext{
${ }^{44}$ Hassemer, Winfried (1995). "Derecho penal simbólico y protección de bienes jurídicos”. En: Pena y Estado, Santiago: Editorial Jurídica Conosur, pp. 23-36.

45 Problem Solving Courts. Disponible en: <http://www.courtinnovation.org/topic/problem-solving-justice>.

46 Therapeutic jurisprudence. Disponible en: <http://www.law.arizona.edu/depts/upr-intj/>. En Chile: $<$ http://achtj.cl/>.
} 
Para ello, este principio demanda un acercamiento empírico que me parece posible enlazar con la corriente denominada de programas basados en evidencia y que toma distancia de intuicionismos o aproximaciones formales.

Ahora bien, el principio de orientación a las consecuencias, en sede proteccional en justicia de familia, se erige también en un fundamento y un límite para la actividad jurisdiccional, la que no sólo debe, entonces, declarar la protección, sino además controlar y velar que ésta se realice, a riesgo de que si esto no se produce, dicha resolución y la consiguiente intervención quedan deslegitimadas en un estado democrático de derecho. No cualquier intervención estatal en pro de los derechos de niños y niñas vulnerados, entonces, es legítima. Para que sea así debe ofrecer no digamos certeza - porque tal cosa no existe en estas materias-, sino más bien probabilidades de éxito. El sentenciador debe, por consiguiente, ponderar el efecto iatrogénico de toda intervención -que per se disminuye el rol de niños y padres y de todos los sujetos intervenidos-, apreciar si esa transitoria suspensión del derecho a construir el propio relato de vida vale la pena, está justificada en aras de la ganancia probable para ese niño que verá, sólo así, resguardados o reparados sus derechos.

Esto se trasunta en el artículo 147 del Código de Costa Rica que indica: "El juez velará por el cumplimiento efectivo de la resolución dictada".

\subsection{Principio de diligencia excepcional}

La Comisión Interamericana ha establecido este especial principio: "En consideración a la importancia que el derecho internacional de los derechos humanos le atribuye a la familia y dada la gravedad, por su irreversibilidad e irreparabilidad, de los daños que pueden ocasionársele al niño en su relación con sus progenitores, en especial para los niños en la primera infancia, la Comisión y la Corte han fijado un estándar de diligencia de carácter excepcional en lo relativo a las cuestiones referentes a la adopción, la guarda y la custodia del niño" ${ }^{7}$.

El Tribunal Europeo de Derechos Humanos sostuvo recientemente: "Para ser adecuadas, las medidas dirigidas a reunir al progenitor y a su hijo deben ser adoptadas rápidamente, porque el paso del tiempo puede tener consecuencias irremediables para las relaciones entre el niño y los progenitores que no viven con él'48.

A su turno, la Corte Interamericana afirmó: "esta Corte también ha sostenido que en vista de la importancia de los intereses en cuestión, los procedimientos administrativos y judiciales que conciernen la protección de los derechos humanos de personas menores de edad, particularmente aquellos procesos judiciales relacionados con la adopción, la

${ }^{47}$ Comisión Interamericana de Derechos Humanos (2013), p. 199 No 87.

${ }^{48}$ Saleck Bardi c. España (2011), No 52. Más adelante el fallo añade: "El Tribunal constata la existencia de falta de diligencia en el procedimiento llevado a cabo por las autoridades responsables de la prolongación de la estancia de la menor en España". (No 58). 
guarda y la custodia de niños y niñas que se encuentra en su primera infancia, deben ser manejados con una diligencia y celeridad excepcionales por parte de las autoridades" ${ }^{49}$.

Y en el mismo fallo detalló algunos criterios para apreciar la diligencia extraordinaria: "La falta de razonabilidad en el plazo constituye, en principio, por sí misma, una violación de las garantías judiciales. En ese sentido, la Corte ha considerado los siguientes elementos para determinar la razonabilidad del plazo: a) complejidad del asunto; b) actividad procesal del interesado; c) conducta de las autoridades judiciales, y d) afectación generada en la situación jurídica de la persona involucrada en el proceso" 50 . Para posteriormente radicar en el Estado el peso de esta prosecución diligente: "la Corte advierte que, en un caso como el presente, la responsabilidad de acelerar el procedimiento recae sobre las autoridades judiciales, en consideración del deber de especial protección que deben brindar a la niña por su condición de menor de edad, y no en la actividad procesal del padre" ${ }^{51}$.

Los profesores Espejo y Lathrop ${ }^{52}$ en un reciente estudio conciben este principio del siguiente modo: "el principio de diligencia excepcional consiste en que la autoridad pública y todo órgano, servicio e institución que conforme el sistema de protección especial de derechos de NNA [niños, niñas y adolescentes], debe actuar con un cuidado superior al ordinario al acometer las funciones que dicho sistema le confiere”.

\subsection{Inmediación}

Los artículos 9o y 12 de la ley No 19.968 explicitan el principio de inmediación, el cual resulta ser consustancial al debido proceso y a la oralidad. Sin embargo, hay cuestiones que en justicia de familia aún no son homogéneamente respondidas respecto a este principio.

¿Abarca también al consejero(a) técnico(a)? ¿Qué ocurre con pericias en las

que la pregunta que se pide responder constituye una verdadera delegación de funciones? Ya existe al menos un fallo de Corte de Apelaciones que reprocha a judicatura de instancia haber cedido a un programa la determinación de la forma de realización del régimen de relación directa y regular.

¿No infringe este principio la práctica judicial de delegar en directores de hogares la determinación del régimen de relación directa y regular del niño internado con sus padres?

¿Es posible la inmediación con juicios que demoran un año, con audiencias distantes entre sí por varios meses? La inmediación tiene un fin, cual es que la

\footnotetext{
${ }^{49}$ Fornerón e hija Vs. Argentina, No 51.

${ }^{50}$ Fornerón e hija Vs. Argentina, No 66.

${ }^{51}$ Fornerón e hija Vs. Argentina, No 69.

52 Espejo Yaksic, Nicolás y Lathrop Gómez, Fabiola (2015). Hacia un rediseño normativo del sistema de protección especial de derechos de niños, niñas y adolescentes en Chile. Santiago: UNICEF, p. 49.
} 
sentencia se base en la información producida directamente, ante la vista y oído del juez de familia. Pero si se han espaciado tanto las audiencias, por varios meses, ¿cómo es posible suponer que el juez va a recordar, en medio de cientos de causas, la información que se produjo al inicio del juicio?

Compárese nuestra regulación con el art. 178 del Código de la Niñez y Adolescencia de Paraguay:

“(...) No siendo posible producir todas las pruebas en un mismo día, el Juez puede prorrogarla para el día siguiente hábil y así sucesivamente hasta que se hayan producido integramente, sin necesidad de otra citación que la que se hará en el acto. Concluidas las mismas, se escucharán los alegatos de las partes por su orden. Culminados los alegatos, el Juez llamará autos para sentencia”.

Un mecanismo para paliar ese natural olvido al que recurre la judicatura es pedirle a consejeros técnicos que escuchen los audios y luego le cuenten la causa, una verdadera relación. ¿Esta relación de audios no infringe acaso también la inmediación?

Es igualmente preocupante y opaco el funcionamiento del sistema de tramitación de escritos por vía de correo electrónico, donde a veces se desechan o se tienen por no presentados escritos sin que exista una autoridad judicial tomando esa decisión ni una resolución que lo consigne, sino simplemente un correo electrónico.

Estas preguntas evidencian que pese a su aparente llaneza, es un principio que genera aún muchas conjeturas que este trabajo no puede responder, pero al menos sí plantear.

\subsection{Separación de familia de origen como ultima ratio}

El Anuario 2014 de Sename no entrega directamente la magnitud de niños separados de sus padres, pero a partir de los datos contenidos en ese informe -en particular en la tabla No $46^{53}$ - es posible estimar en 21.761 la cantidad de niños y niñas en esta situación durante el año 2014, una cifra muy preocupante.

El artículo 35 de la Ley de protección integral de los derechos del niño de Argentina concibe así este principio:

"Artículo 35.- Aplicación. Se aplicarán prioritariamente aquellas medidas de protección de derechos que tengan por finalidad la preservación y el fortalecimiento de los vínculos familiares con relación a las niñas, niños y adolescentes. Cuando la amenaza o violación de derechos sea consecuencia de necesidades básicas insatisfechas, carencias o dificultades materiales, económicas, laborales o de vivienda, las medidas de protección son los programas dirigidos a brindar ayuda y apoyo incluso económico, con miras al mantenimiento y fortalecimiento de los vinculos familiares".

53 CREAD Mayores 2.423; CREAD Lactantes y preescolares 500; Centros Residenciales 12.785; Programas FAE 5.041; FAS 1.012. 
La Convención sobre Derechos del Niño en diversos artículos $-5^{\circ}, 11,16$, 18, 2021 y principalmente el $9^{\circ}$ - es sobradamente explícita a este respecto. La separación de sus padres es sin duda alguna una medida de ultima ratio cuando se han desplegado una serie de esfuerzos y se encuentra en grave riesgo o se ha producido ya un daño a la integridad física o psíquica del niño. Nada menos que esto autoriza una decisión de este tipo.

Nuestra Corte Suprema sostiene, luego de citar los artículos 30 de la Ley de Menores y 74 de la Ley de Tribunales de Familia, en un caso muy interesante, lo siguiente:

"Séptimo: Que como puede apreciarse la decisión de los sentenciadores contenida en el fallo que se impugna, no se sustenta en ninguna de las hipótesis que la ley contempla y bajo cuyo amparo se justifica y legitima la aplicación de una medida de la naturaleza de la dispuesta, esto es, aquélla que ordena la internación de una niña menor de edad en un centro de protección, provocando la separación de su familia. En efecto, los jueces del grado, no obstante, disponer una medida tan gravosa y radical como es la de que se trata, no justifican su aplicación del modo que lo prescribe la ley, es decir, bajo la premisa de no existir otra posibilidad de brindar el amparo necesario a la menor que no sea esta privación de su hogar de origen, no satisfaciéndose, asi la exigencia de fundamentación adicional, a toda resolución judicial, que ha establecido el legislador, en la materia"s4.

En el mismo sentido:

"Décimo: Que en cuanto a las habilidades parentales de la madre, si bien aparecen como deficientes, no resultan de tal entidad que justifique separarla de sus hijos, máxime si se han constatado mejoras en su comportamiento, pues es un hecho de la causa que fue la requerida quien los inscribió en el Registro Civil y los insertó en los sistemas comunales de salud y educación y que ésta ha mejorado en su rol de madre.

En cuanto a la oportunidad de la medida, cabe señalar que de los hechos que se dieron por acreditados, no consta que respecto de la requerida y de los niños cuya internación se ordena se hayan aplicado, con anterioridad, otras medidas tendientes a capacitarla en su rol parental y protegerlos en sus derechos.

Undécimo: Que por lo antes señalado, y por controvertir el claro tenor de la ley, al disponer la medida de internación sin antes intentar una menos gravosa respecto de los niños y su madre y en ausencia de una grave afectación de derechos que lo amerite, los sentenciadores del grado cometieron un error de derecho que debe ser subsanado por esta vía"s5.

La excepcionalidad de la separación de los padres se expresa tanto en intensidad como en duración.

\footnotetext{
${ }^{54}$ Corte Suprema, "Medida de protección reservada", 9 de septiembre de 2010, rol No 5323-2010 Redacción del ministro Patricio Valdés.

55 Corte Suprema, “Arriagada con Ticona”, 10 de septiembre de 2009, rol No 3784-2009. Redacción del abogado integrante Patricio Figueroa S.
} 
No cumple con este estándar el fallo de Corte de Santiago del 2006 donde es a través del voto disidente del ministro Zepeda que nos enteramos que existía la posibilidad de no internar a los niños, sino dejarlos provisoriamente con un familiar (el padre y el tío de los niños):

"En efecto, si bien el artículo 30 de la Ley de Menores autoriza al Juez para disponer el ingreso de los niños a un centro de tránsito o distribución, restringiéndole la libertad de movimiento como medida de protección, la misma norma determina que se preferirá siempre que asuman provisoriamente el cuidado de éstos sus parientes consanguineos, privilegiando de este modo la libertad personal.

Tal facultad, sin duda, tiene en consideración que uno de los aspectos más desarrollados de los tratados sobre derechos humanos, es el establecimiento de mecanismos de protección del derecho a la libertad personal, y la injerencia en ella por la autoridad pública fija modalidades y formalidades que deben cumplirse estrictamente, de acuerdo a los fines que la justifican"56.

Un ejemplo de la limitación en el tiempo está al final del artículo 39 de la regulación argentina:

"Artículo 39.- Medidas excepcionales. Son aquellas que se adoptan cuando las niñas, niños $y$ adolescentes estuvieran temporal o permanentemente privados de su medio familiar o cuyo superior interés exija que no permanezcan en ese medio.

Tienen como objetivo la conservación o recuperación por parte del sujeto del ejercicio y goce de sus derechos vulnerados y la reparación de sus consecuencias.

Estas medidas son limitadas en el tiempo y sólo se pueden prolongar mientras persistan las causas que les dieron origen".

\section{CONCLUSIONES}

Las líneas que anteceden contienen una proposición de principios específicos de este procedimiento, que están llamados erigirse en el eje teleológico de una hermenéutica que aplique la Convención de Derechos del Niño y los demás tratados internacionales atingentes y que configuran el marco normativo de la forma en que nuestro sistema judicial protege derechos de niños.

\section{BiBLIOGRAFÍA CITADA}

Aldunate Lizana, Eduardo (2011). "Principios jurídicos y neoconstitucionalismo". En: Principios jurídicos. Análisis y crítica, Santiago: Thompson Reuters y Abeledo Perrot.

\footnotetext{
${ }^{56}$ Corte de Apelaciones de Santiago, “Bascuñán Méndez y otros”, 4 de diciembre del 2006, rol № 14595-2006.
} 
AleXY, Robert (1988). "Sistema jurídico, principios jurídicos y razón práctica". Doxa. Cuadernos de Filosofía del Derecho, No 5, pp. 139-151.

Atria Lemaitre, Fernando (2011): "Lo que importa sobre los principios". En: Principios jurídicos. Análisis y critica, Santiago: Thompson Reuters y Abeledo Perrot.

Benavente Moreda, Pilar (2011). "Riesgo, desamparo y acogimiento de menores: Actuación de la administración e intereses en juego". Anuario de la Facultad de Derecho de la Universidad Autónoma de Madrid, No 15, pp. 15-62.

Biblioteca del Congreso Nacional (2004). Historia de la ley No 19.968, que crea los tribunales de familia.

Carretta Muñoz, Francesco (2014). "La desformalización del proceso judicial de familia e infancia". Revista de derecho (Valparaíso), Vol. 42, pp. 481-495.

Coloma Correa, Rodrigo (2011). "Los principios como analgésicos ante lagunas, inconsistencias e inequidades de los sistemas jurídicos”. En: Principios jurídicos. Análisis y critica, Santiago: Thompson Reuters y Abeledo Perrot.

Comité de Derechos del Niño (2009). Observación general No 12. El derecho del niño a ser escuchado. CRC/C/GC/12.

Comité de Derechos del Niño (2013). Observación general No 14. Sobre el derecho del niño a que su interés superior sea una consideración primordial (artículo $3^{\circ}$, párrafo 1). CRC/C/GC/14.

Couso Salas, Jaime (2006). "El niño como sujeto de derechos y la nueva Justicia de Familia. Interés superior del niño, autonomía progresiva y derecho a ser oído". Revista de Derechos del Niño, Vol. 3-4, pp. 145-166.

DWORKIn, Ronald (1984). Los derechos en serio. Barcelona: Ariel.

Espejo YaKsic, Nicolás (2014). Hacia una Reforma Integral del Sistema Penal de Adolescentes en Chile: el Desafío de la Especialización, Serie reflexiones Infancia $y$ adolescencia $N^{o}$ 18. Santiago: UNICEF.

EsPejo YaKSIC, Nicolás y LATHRop GÓMEZ, Fabiola (2015). Hacia un rediseño normativo del sistema de protección especial de derechos de niños, niñas y adolescentes en Chile. Santiago: UNICEF.

Estrada Vásquez, Francisco (2014). Nueva infraestructura y justicia de familia. Documento de Estudio No 3. Disponible en: <https://es.scribd.com/ doc/237506447/ESTRADA-Doc-Estudio-3-2014-Nueva-Infraestructura-yJusticia-de-Familia>. [Consulta: 15 octubre 2015].

Estrada Vásquez, Francisco (2015). "La ilusión de la protección”. Revista de Familias y Terapias, Instituto Chileno de Terapia Familiar.

Fantuzzo, John W. y Mohr, Wanda K. (1999). "Prevalence and Effects of Child Exposure to Domestic Violence". The Future of Children. Domestic violence and children, Vol. 9, No 3.

Gajardo, Samuel (1929). Los derechos del niño y la tiranía del medio ambiente (Divulgación de la ley $N^{\circ}$ 4.447). Santiago: Imprenta Nascimento. 
Hassemer, Winfried (1995). "Derecho penal simbólico y protección de bienes jurídicos”. En: Pena y Estado, Santiago: Editorial Jurídica Conosur, pp. 23-36.

Home Office (2001). The Youth Court 2001. The Changing Culture of the Youth Court. Good Practice Guide. Disponible en: <https://www.justice. gov.uk/downloads/youth-justice/courts-and-orders/YouthCourt2001.pdf>. [Consulta: 15 octubre 2015].

Jara Castro, Eduardo (2011). Derecho procesal de familia. Santiago: Editorial Jurídica de Chile.

Jeldres Salazar, Mónica et al. (2012). Proyecto de levantamiento y unificación de información referente a los niños, niñas y adolescentes en sistema residencial de la $\checkmark$ región. Poder judicial.

LANSDOWn, Gerison (2005). La evolución de las facultades del niño. Unicef y Save the Children: Instituto de Investigaciones Innocenti de UNICEF.

LÁzAro, I. (Coord.). La protección de los menores. Estudio de derecho comparado (España, Alemania, Francia, Inglaterra e Italia). Grupo de Investigación Interdepartamental "Derecho y Menores", Madrid: Facultad de Derecho, Universidad Pontificia Comillas de Madrid-Fundación Diagrama.

Nino, Carlos (1974). Consideraciones sobre la dogmática jurídica. México: Universidad Nacional Autónoma de México.

NúNEzZ Romero, Germán (2010). "La judicatura de familia ¿Tutela efectiva de los Derechos de los Menores?: Las medidas de protección en el Derecho chileno”. Revista Chilena de Derecho de Familia, No 3, pp. 245-278.

NúÑEz Ávila, René y Cortés Rosso, Mauricio (2012). Derecho Procesal de Familia. La primera reforma procesal civil en Chile. Santiago: Thomson Reuters.

Peña González, Carlos (2002). "Prólogo". En: Introducción al Nuevo Proceso Penal, Santiago: Ediciones Universidad Diego Portales.

Platt, Anthony (2001). Los Salvadores de los Niños o la Invención de la delincuencia. México: Ediciones Siglo XXI, tercera edición.

Sename (2015). Anuario estadístico 2014. Servicio Nacional de Menores.

Suprema Corte de Justicia de la Nación (2012). Protocolo de actuación para quienes imparten justicia en casos que afecten a niños. México.

UniCEF (2012). Nueva Institucionalidad de Infancia y Adolescencia en Chile. (Aportes de la sociedad civil y del mundo académico). Serie reflexiones Infancia y adolescencia, No 13, Santiago: UNICEF.

Vargas, Macarena, Correa, Paula, Barros, Paula et al. (2010). Niños, niñas y adolescentes en los tribunales de familia. Informe final de estudio (Facultad de Derecho, Universidad Diego Portales y UNICEF Chile).

Vargas Pávez, Macarena y Correa Camus, Paula (2011). "La voz de los niños en la justicia de familia de Chile". Ius et Praxis, Vol. 17, No 1, pp. 177-204. 
Vergara Blanco, Alejandro (2012). "Los principios jurídicos y la tarea de construir el Derecho Administrativo en clave científica". Revista de Derecho Administrativo, No 6, pp. 63-80.

Vivanco Martínez, Angela (2009). "Negativa de un menor de edad y de su familia a que este reciba una terapia desproporcionada o con pocas garantías de efectividad. Apelación de medida de protección otorgada por la jueza de familia de Valdivia. Sentencia de la I. Corte de Apelaciones de Valdivia, de 14 de mayo de 2009". Revista Chilena de Derecho, Vol. 36, No 2, pp. 399-440.

ZERMATTEN, Jean (2003). El interés superior del niño. Del análisis literal al alcance filosófico. Informe de trabajo 3-2003, Institut International des Droits de l'Enfant.

\section{NORMAS CITADAS}

Ley No 2.675, sobre protección a la infancia desvalida, Diario Oficial, 4 de septiembre de 1912.

Ley No 16.618, Ley de Menores, Diario Oficial, 8 de marzo de 1967.

Ley No 19.968, Ley de Tribunales de Familia, Diario Oficial, 30 de agosto de 2004.

Ley No 20.032, establece sistemas de atención a la niñez y adolescencia a través de la red de colaboradores del Sename, y su régimen de subvención, Diario Oficial, 25 de julio de 2005.

Ley 20.084, establece un sistema de responsabilidad de los adolescentes por infracciones a la ley penal, Diario Oficial, 7 de diciembre de 2005.

D.S. No 839, del Ministerio Relaciones Exteriores, de 1990, aprueba Convención sobre los Derechos del Niño, Diario Oficial, 27 de septiembre de 1990.

Acta No 37-2014, Auto Acordado que regula el seguimiento de medidas de internación y visitas a los Centros Residenciales por los Tribunales de Familia en Coordinación con el Servicio Nacional de Menores y el Ministerio de Justicia, de 14 de marzo de 2014.

Acta No 135-2010. Auto Acordado del Centro de Medidas Cautelares de los Cuatro Tribunales de Familia de Santiago, de 3 de septiembre de 2010.

Acta No 93-2005. Auto acordado sobre el rol y funciones de los Consejos Técnicos en los Juzgados de Familia, de 12 de septiembre de 2005.

Acta No 237-2014. Auto Acordado que regula la implementación y uso de un espacio adecuado para el ejercicio del derecho a ser oídos de niños, niñas y adolescentes en tribunales con competencia en materia de familia

\section{NORMAS INTERNACIONALES CITADAS}

Reglas Mínimas de Naciones Unidas para la protección de menores privados de libertad, 14 de diciembre de 1990.

Directrices de Naciones Unidas para el cuidado alternativo. 


\section{NORMAS EXTRANJERAS CITADAS}

Código de la Niñez y la Adolescencia de Costa Rica.

Código de la Niñez y la Adolescencia, ley No 17.823, de Uruguay.

Código de la Infancia y la Adolescencia de Colombia.

\section{JURISPRUDENCIA CITADA}

Corte Suprema, "Arriagada con Ticona", 10 de septiembre de 2009, rol No 3784-2009.

Corte Suprema, "Meza con De la Rivera”, 16 de agosto de 2010, rol No 4307-2010.

Corte Suprema, "Medida de protección reservada", 9 de septiembre de 2010, rol No 5323-2010.

Corte Suprema, "Medida de protección reservada", 4 de abril de 2011, rol No 9917-2010.

Corte Suprema, "Herrera con González y otros", 14 de enero de 2013, rol No $7150-2012$.

Corte Suprema, "Segovia con Valdivia”, 12 de junio de 2013, rol No 2522-2013.

Corte de Apelaciones de Santiago, "Arévalo Araneda", 25 de abril de 2003, rol No 9818-2003

Corte de Apelaciones de Santiago, "Ayala Armijo", 14 de mayo de 2003, rol No 11876-2003.

Corte de Apelaciones de Santiago, "Acosta Larenas", 11 de junio de 2003, rol No $13965-2003$.

Corte de Apelaciones de Santiago, "Bascuñán Méndez y otros", 4 de diciembre del 2006, rol No 14595-2006.

Corte de Apelaciones de Valdivia, "Medida de protección reservada", 14 de mayo del 2009, rol No 103-2009.

Corte de Apelaciones de Santiago, "Medida de protección reservada", 2 de noviembre de 2010, rol No 1878-2010.

Corte de Apelaciones de Concepción, "Medida de protección reservada", 18 de enero de 2011, rol No 495-2010.

\section{JURISPRUDENCIA EXTRANJERA CITADA}

Corte Suprema de los Estados Unidos de América, In re Gault 387 U.S. 1; 87 S. Ct. 1428.

Corte Interamericana de Derechos Humanos, Opinión Consultiva OC-17/2002.

Tribunal Europeo de Derechos Humanos. Caso Saleck Bardi c. España. Demanda No 66167/09. Sentencia de 24 de mayo de 2011. 